\title{
Analysis of Climate and Land Use Changes Impacts on Land Degradation in the North China Plain
}

\author{
Zhihui Li, ${ }^{1,2,3}$ Xiangzheng Deng, ${ }^{1,2}$ Fang Yin, ${ }^{4}$ and Cuiyuan Yang ${ }^{5}$ \\ ${ }^{1}$ Institute of Geographic Sciences and Natural Resources Research, Chinese Academy of Sciences, Beijing 100101, China \\ ${ }^{2}$ Center for Chinese Agricultural Policy, Chinese Academy of Sciences, Beijing 100101, China \\ ${ }^{3}$ University of Chinese Academy of Sciences, Beijing 100049, China \\ ${ }^{4}$ Leibniz Institute of Agricultural Development in Transition Economies (IAMO), Theodor-Lieser Street 2, \\ 06120 Halle (Saale), Germany \\ ${ }^{5}$ College of Geomatics, Shandong University of Science and Technology, Qingdao, Shandong 266590, China
}

Correspondence should be addressed to Xiangzheng Deng; dengxz.ccap@gmail.com

Received 19 September 2014; Accepted 6 December 2014

Academic Editor: R. B. Singh

Copyright @ 2015 Zhihui Li et al. This is an open access article distributed under the Creative Commons Attribution License, which permits unrestricted use, distribution, and reproduction in any medium, provided the original work is properly cited.

Land degradation is a complex process which involves both the natural ecosystem and the socioeconomic system, among which climate and land use changes are the two predominant driving factors. To comprehensively and quantitatively analyze the land degradation process, this paper employed the Normalized Difference Vegetation Index (NDVI) as a proxy to assess land degradation and further applied the binary panel logit regression model to analyze the impacts of the driving factors on land degradation in the North China Plain. The results revealed that an increase in rainfall and temperature would significantly and positively contribute to the land improvement, and conversion from cultivated land to grassland and forest land showed positive relationship with land improvement, while conversion to built-up area will lead to land degradation. Besides, human agricultural intensification represented by fertilizer utilization will help to improve the land quality. The economic development may exert positive impacts on land quality to alleviate land degradation, although the rural economic development and agricultural production will exert negative impacts on the land and lead to land degradation. Infrastructure construction would modify the land surface and further resulted in land degradation. The findings of the research will provide scientific information for sustainable land management.

\section{Introduction}

Land degradation has become a critical issue worldwide, especially in the developing countries, which leads to great concerns about food security. To improve livelihoods of human beings and to keep sustainable development of human society, healthy land ecosystems are basically essential elements. However, the key services of good quality land and their true values have been usually taken for granted and underestimated, leading to serious land degradation, which not only deteriorates the ecosystem services but also hinders regional sustainable development. Land degradation means a significant reduction of the productive capacity of land. It is an interactive process involving various casual factors, among which climate changes, land use/cover changes, and human dominated land management play a significant role [1-4].
Land degradation involves two interlocking complex systems, the natural ecosystem and the human social system, and both changes in biophysical natural ecosystem and socioeconomic conditions will affect the land degradation process [5]. Natural forces affect land degradation through periodic stresses of extreme and persistent climatic events. Human activities also contribute to land degradation through deforestation, removal of natural vegetation, and urban sprawl that lead to land use/cover changes; unsustainable agricultural land use management practices, such as use and abuse of fertilizer, pesticide, and heavy machinery; and overgrazing, improper crop rotation, poor irrigation practices, and so forth [6].

In comparison to other regions, land degradation afflicts China more seriously in terms of the extent, intensity, economic impacts, and affected population [7]. China accounts for $22 \%$ of the world's population but only $6.4 \%$ of the global 
land area and $7.2 \%$ of the global cultivated land area. Agricultural production is an important issue that always plagues the national economy and livelihood of citizens [8]. However, the rapid population growth and urbanization, unreasonable human utilization, and influence of natural factors have caused degradation of 5.392 million $\mathrm{km}^{2}$ of land, which accounts for about $56.2 \%$ of the total national area [9]. Only 1.3 million $\mathrm{km}^{2}$ of land is suitable for cultivation in China, which accounts for about $14 \%$ of the total national land area. The land degradation has involved more than half of the total cultivated land area and further exerts more pressure on the economic benefits of agricultural production and food security. Besides, as the cultivated land degradation will directly affect the potential land productivity, more inputs such as fertilizer and irrigation water will be needed in order to get the same production as well as yield level, which will increase the production cost [10]. In addition, the structural change and pattern succession of the land system resulting from land conversions will undoubtedly lead to changes in the suitability and quality of land and directly influence land productivity [11]. Hence sustainable productive land management is crucial for the country's long-term agricultural economy.

China is a large country with significant spatial variation of natural/climatic conditions and diverse socioeconomic characteristics. For example, the eastern, central, and western part of China have different population density, industrial structure, per capita income, and so forth. The difference among regions will affect the land use, leading to difference in the way and extent of economic use of land resources [12]. The North China Plain has been one of the most productive agricultural bases in China for thousands of years. It is of great significance to quantitatively measure the intensity and spatial pattern of land degradation and analyze the driving mechanisms, which can provide information for sustainable land management to ensure the food safety in the North China Plain.

In order to provide information for sustainable land management, it is necessary to quantitatively clarify the impacts of major natural and socioeconomic driving forces on land degradation. The recent development of remote sensing techniques (RS) and geographic information system (GIS) techniques has enhanced the capabilities to obtain and handle spatial information on the heterogeneities of land surface characteristics. The integration of RS and GIS technologies has been proven to be an efficient approach and has been successfully used in various investigations for land degradation assessment. Land degradation is a long-term process indicating the loss of ecosystem function and productivity. For quantitative analysis of land degradation, satellite measurements of the Normalized Difference Vegetation Index (NDVI), which is the most widely used proxy for vegetation cover and production, have been widely applied in studies of land degradation from the field scale to national and global scales $[7,13-15]$. Therefore, the objective of this study is to explore the spatial pattern and temporal variation of land degradation based on NDVI in the North China Plain and then to analyze the impact mechanisms of a set of natural and socioeconomic driving forces on land degradation, with the application of the binary panel logit regression model.

\section{Data Processing and Analyses}

2.1. An Overview of the North China Plain. The North China Plain $\left(32^{\circ} 08^{\prime}-40^{\circ} 16^{\prime} \mathrm{N}, 112^{\circ} 10^{\prime}-122^{\circ} 40^{\prime} \mathrm{E}\right)$ is one of the most significant grain production regions of China. It covers two metropolises (Beijing and Tianjin) and five provinces including Anhui, Hebei, Henan, Jiangsu, and Shandong. As it is an alluvial plain developed by the intermittent flooding of the Huanghe, Huaihe, and Haihe rivers, it is also known as Huang-Huai-Hai Plain in China (Figure 1).

As estimated with the remote sensing data derived from the Landsat TM and ETM+ images in the year 2008, the cultivated land accounts for about $68 \%$ of the total land area of the North China Plain (Figure 2). There is a semiarid to semihumid warm temperate climate in the North China Plain, with the average annual temperature of $10^{\circ} \mathrm{C}-15^{\circ} \mathrm{C}$ and annual rainfall of $500-800 \mathrm{~mm}$. It is evident that the North China Plain is suitable for developing rain-fed agriculture and planting a variety of crops and fruit trees. Meanwhile, it is conducive to mechanization and irrigation with its natural conditions of a flat terrain, deep soil, and contiguous land concentration. All of these unique conditions have made the North China Plain a major agricultural region and a significant commodity base for grain, cotton, meat, and oil in China [16].

However, the rapid population growth and urban land expansion have led to serious cultivated land loss and environmental degradation in the North China Plain. Many researches showed that the conversion from cultivated land to other types of land led to the decrease of cultivated land in the North China Plain [11, 16, 17]. Among the researches, Shi et al. (2013) pointed out that the area of cropland abandonment was much greater than the area of cropland reclamation in the North China Plain [17]. Besides, the quality of cultivated land converted to other land use types is generally higher than that of the cultivated land converted from other land use types [11]. As a result, the shrinkage of cultivated land in the North China Plain will exert great impact on the land quality. How to improve land productivity is becoming vital for the improvement of agricultural production. In addition, though the statistic data showed that the grain yields were increasing, it is due to the additional investment into the agricultural production. In this regard, it is an urgent issue to study how to make scientific policy and sustainable land management measures to rationally regulate the land conversion and control land degradation to improve the productivity of the remaining resources in the agricultural sector.

2.2. Data Preparation. According to previous studies, driving factors of land degradation are complex, among which biophysical causes (including topography that determines soil erosion hazard and climatic conditions, such as rainfall and temperature) and land use change (such as deforestation, desertification resulting from unsustainable land management practices) are major direct contributors to land 


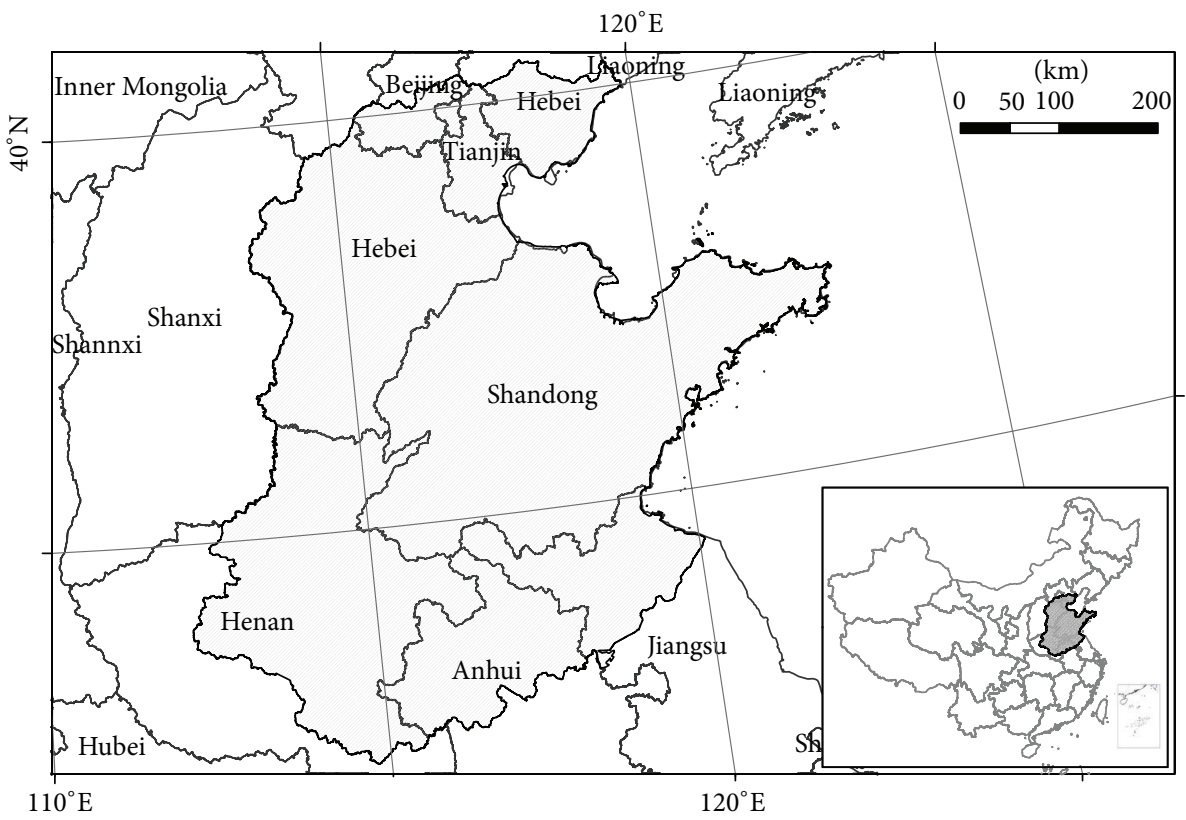

Figure 1: Location of the North China Plain.
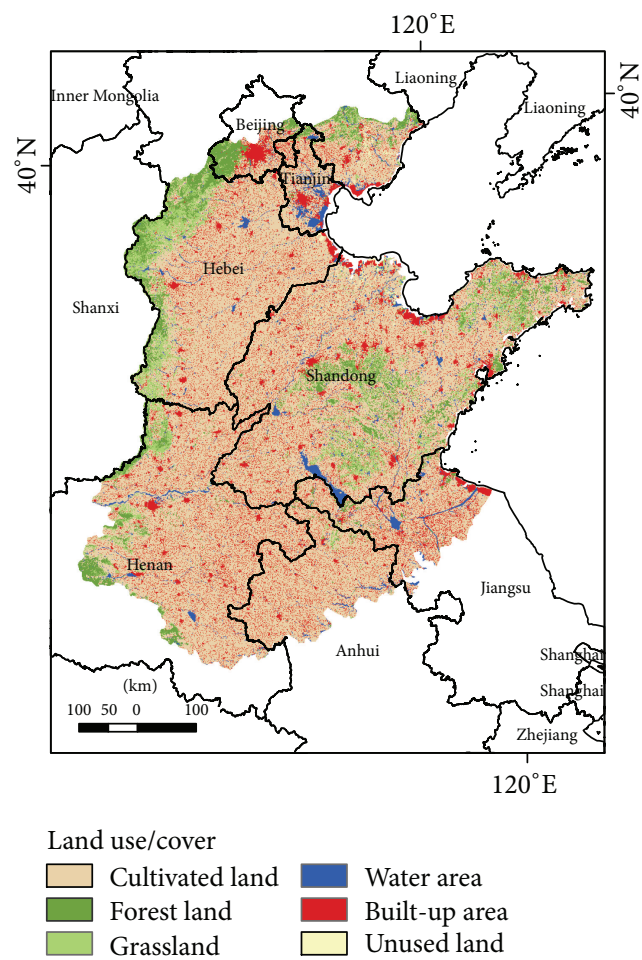

Figure 2: Land use pattern of the North China Plain in the year 2008.

degradation, while the underlying causes of land degradation include population density, economic development, land tenure, and access to agricultural extension, and infrastructure. Thus, in order to analyze the situation of agricultural production and impact mechanisms of climate and land use changes integrated with socioeconomic factors on cultivated land degradation in the North China Plain, we collected the
NDVI data, land use datasets, climatic data, socioeconomic statistical data, and other geophysical data of the years 20002008.

NDVI. NDVI is one of the most commonly used indicators for vegetation monitoring [18, 19]. Many previous studies have used the NDVI and other measures based on the NDVI 
as indicators of changes in ecosystem productivity and land degradation, which showed that NDVI is strongly correlated with the green vegetation coverage [20]. Though there are some limitations and criticisms related to the use of this measure, NDVI remains the only dataset available at the global level and the only dataset that reliably provides information about the condition of the aboveground biomass [21, 22]. In this study, we used the remote sensing data of NDVI to measure the land degradation. Before 2006, the NDVI data was obtained from the GIMMS NDVI dataset produced by the GLCF (Global Land Cover Facility) research group at the University of Maryland from July 1981 to December 2006, with a spatial resolution of $8 \mathrm{~km}$ by $8 \mathrm{~km}$ and a temporal resolution of 15 days. The NDVI data after the year 2006 was derived from SPOT VEGETATION data (ten-day ensembles) which were derived from a dataset developed over the period from April 1998 to December 2010, with a spatial resolution of $1 \mathrm{~km}$ by $1 \mathrm{~km}$. Based on the period when the two datasets overlapped (1998 to 2006), we conducted data processing according to the previous experience of Yin et al. (2014) [23]. Firstly, correlation analysis between the maximum monthly NDVI and other factors was performed, following which a linear regression equation was established to extend the GIMMS (Global Inventory Modeling and Mapping Studies) dataset from 2007 to 2008. This helps to eliminate any sensor errors in the other two datasets [24]. To ensure the data quality, reliable and internationally recognized data pretreatment processes were used [25]. In order to eliminate cloud contamination effects and the noise caused by other atmospheric phenomena, we included a smoothing method proposed by Chen et al. [26] based on the Savitzky-Golay filter. Finally, we clipped the NDVI data of the North China Plain during the period from the year 2000 to 2008 .

Land Use. The land use data came from the land use database of the Resources and Environment Scientific Data Center, Chinese Academy of Sciences [11, 27, 28]. The database was constructed from remotely sensed digital images by the US Landsat TM/ETM satellite with a spatial resolution of 30 by 30 meters. Further the land use data are upscaled to 1 by 1 kilometer. The data that was analyzed in this study covered the years 2000 and 2008.

Climatic Data. The climatic data, mainly including temperature and rainfall from the year 2000 to 2008 , were derived from the daily records of 117 observation stations covering the entire area of the North China Plain, which were maintained by the China Meteorological Administration. A spline interpolation using the coupling-fitted thin plate interpolation method was chosen to interpolate the meteorological data [29]. Based on the climatic dependence on topography, climatic variables were interpolated with spatial resolution of 1 by 1 kilometer [30]. At a broader scale, temperature declined roughly with the increasing elevation at a typical standard lapse rate of $6.5^{\circ} \mathrm{C}$ per 1 kilometer [31], so the interpolated air temperature data were adjusted to the sea level according to the altitudinal correction factors based on the digital elevation model (DEM) dataset.
Soil Organic Matter. The soil fertility map of the study area was clipped from the soil map of China provided by the Institute of Soil Science, Chinese Academy of Sciences. It was based on the maps on the scale of $1: 4,000,000$ from the Second National Soil Survey of China for Soil Organic Matter (SOM).

Socioeconomic Statistical Data. In this study, we collected and processed the socioeconomic data of 385 major counties in the North China Plain at a county level for the period of the years 2000-2008, including the gross domestic production (GDP), population, rural farmers' per capita income, fertilizer utilization, pesticide utilization, farm machinery, total grain production, and total grain sown area, which were all acquired from socioeconomic statistical yearbooks published by National Statistical Bureau of China.

Geophysical Data. The geophysical data is also closely related with the land productivity. In this specific study, the geographic factors mainly include elevation and average slope, the data of which were derived from China's Digital Elevation Model dataset supplied by the National Geomatics Center of China. Another part of the geophysical data was the proximity variables, including the distance from each grid to the nearest expressway or highway and other ways, which were incorporated to measure the impacts of the infrastructure construction on the land degradation.

\subsection{Primary Analysis}

Changes of Grain Production. We analyzed the changes of grain production and the relationship between total grain production and grain yield $(\mathrm{kg} / \mathrm{ha})$ of the North China Plain during the years 2000-2008. The spatial distribution of grain yield at municipality or county level in the years 2000, 2005, and 2008 is shown in Figure 3. The grains mainly included wheat and maize, but some rice, soybean, and tuber crops were also included.

During the period of the years 2000-2008, annual total grain production of the selected counties of the North China Plain increased by more than $40 \%$, and the average grain yield increased from 4994 to $5986 \mathrm{~kg} / \mathrm{ha}$ (with an increasing rate of 20\%). The time-series changing trend of the total grain production is similar to that of the average grain yield, and therefore the increase of agricultural production can be mainly ascribed to the increase in the average grain yield (Figure 4). The time-series change of grain yield from year 2000 to 2008 can be divided into two periods. Firstly, the average grain yield decreased after the year 2000 because of a decrease in grain price. Secondly, the price of grain increased again through governmental support after the year 2003, which made the average yields recover again.

Also, we showed that the application rates of fertilizer and pesticide increased with fluctuations from 525 to $622 \mathrm{~kg} / \mathrm{ha}$ and from 12.6 to $16.2 \mathrm{~kg} / \mathrm{ha}$ during the period of the years 2000-2008, respectively. The application rate of the farm machinery also showed an increasing trend (Figure 5). The increases of the application of farm machinery, fertilizer, and pesticide can be the key determinants of the increase in crop 


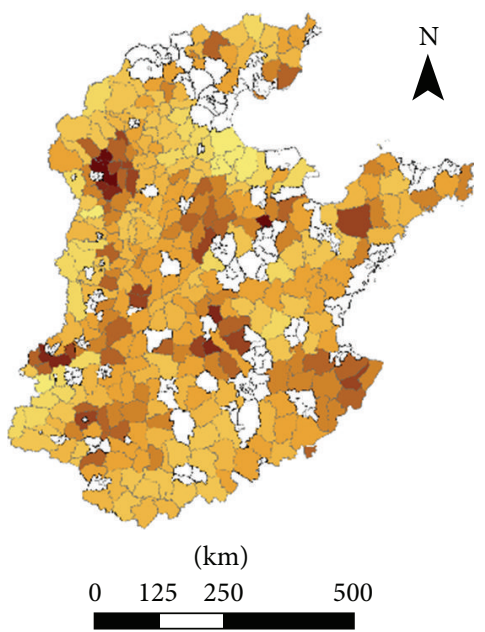

(a)

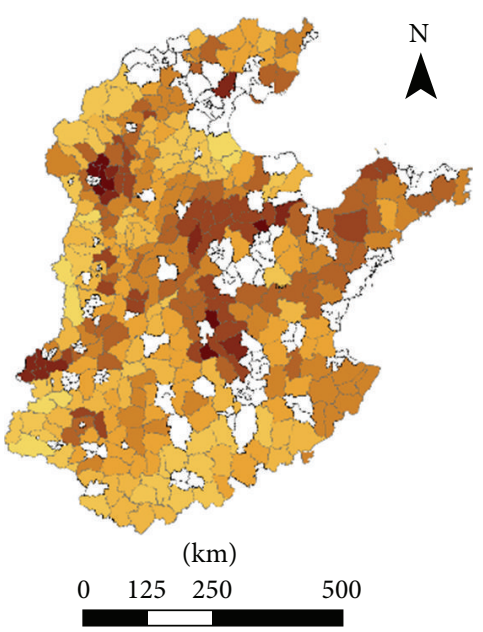

(b)

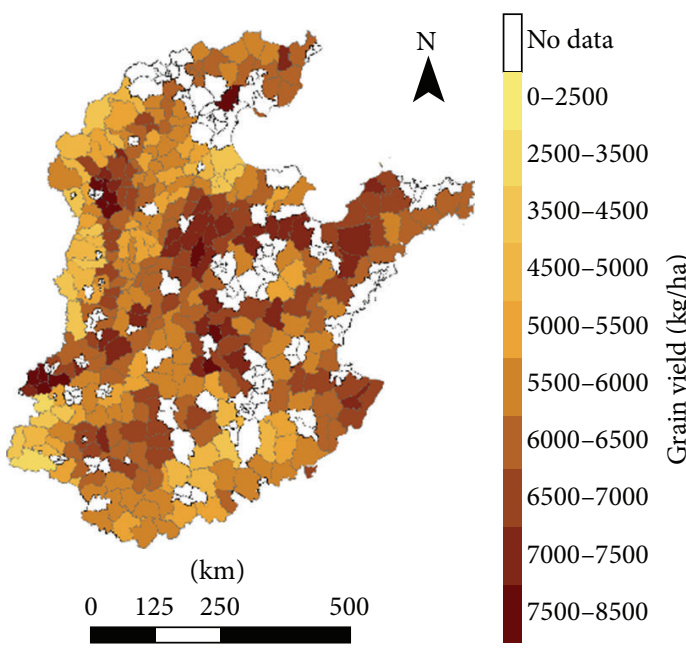

(c)

Figure 3: County-level grain yield of the North China Plain, (a) 2000, (b) 2005, and (c) 2008.

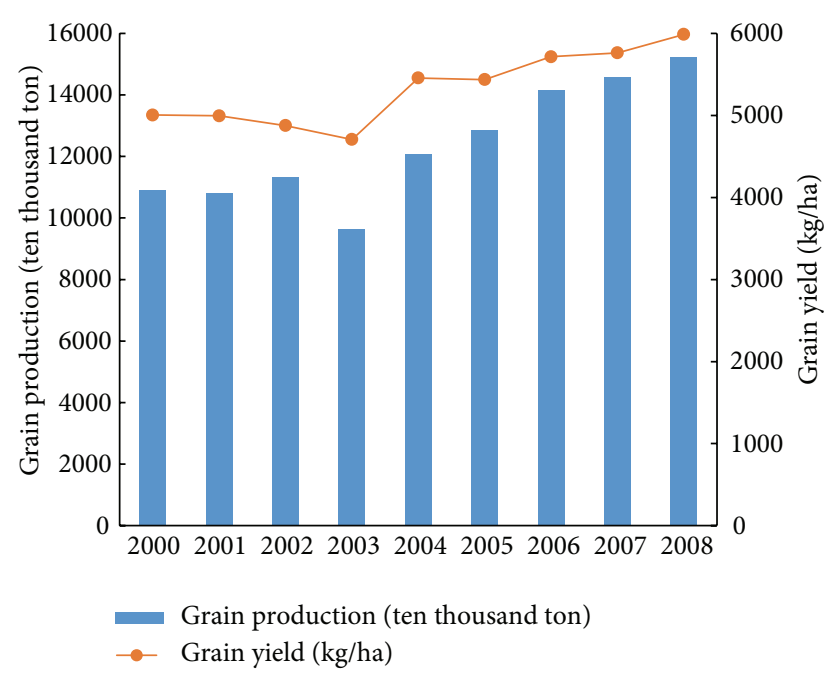

FIGURE 4: Relationship between grain production and grain yield of the North China Plain, 2000-2008.

yield; however, further increases in fertilizer and pesticide application are unlikely to be as effective as they previously were in increasing the grain yields because of the gradually diminishing return rate.

Trends in NDVI. The annual average greenness (represented with NDVI) is chosen as the standard proxy of annual average biomass productivity, which generally fluctuates with the rainfall. The NDVI calculated using remote sensing image data currently is one of the most commonly used indicators to monitor regional or global vegetation and the ecosystem and is the best instruction factor to reflect vegetation growth conditions and coverage [32]. In this study, the cultivated land degradation areas were identified with a sequence of analyses of the NDVI data. The result shows that the annual average NDVI of the North China Plain showed an overall increasing

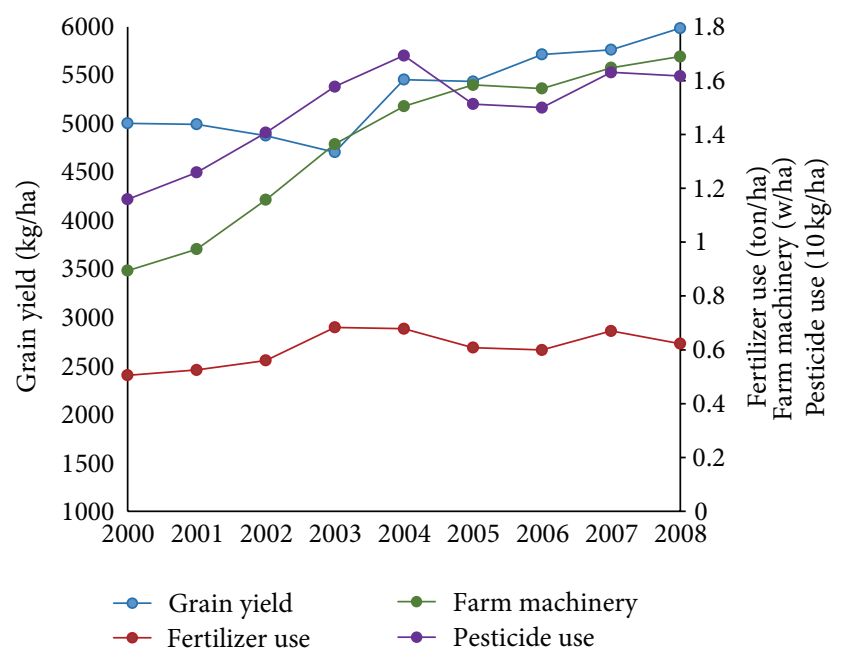

FIGURE 5: Changes of grain yield, fertilizer use, pesticide use, and farm machinery application of the North China Plain, 2000-2008.

trend during the years 2001-2004. About 90\% of the study area's annual average NDVI experienced an increasing trend. While only $5 \%$ of the study area's annual average NDVI showed a decreasing trend, which was distributed in the Shandong Province (Figure 6(a)). In comparison, during the years 2004-2008, about $80 \%$ of the study area's annual average NDVI experienced a decreasing trend, with only $19 \%$ of the study area's annual average NDVI showed an increasing trend (Figure 6(b)). Besides, the annual average NDVI in some areas showed first increasing and then decreasing trend during the years 2000-2008. Overall, the annual average NDVI showed an increasing trend in most parts of the whole study area during the years 2000-2008 (Figure 6(c)).

Land Use Changes. During the years 2000-2008, the land use change is mainly dominated by the conversion from 

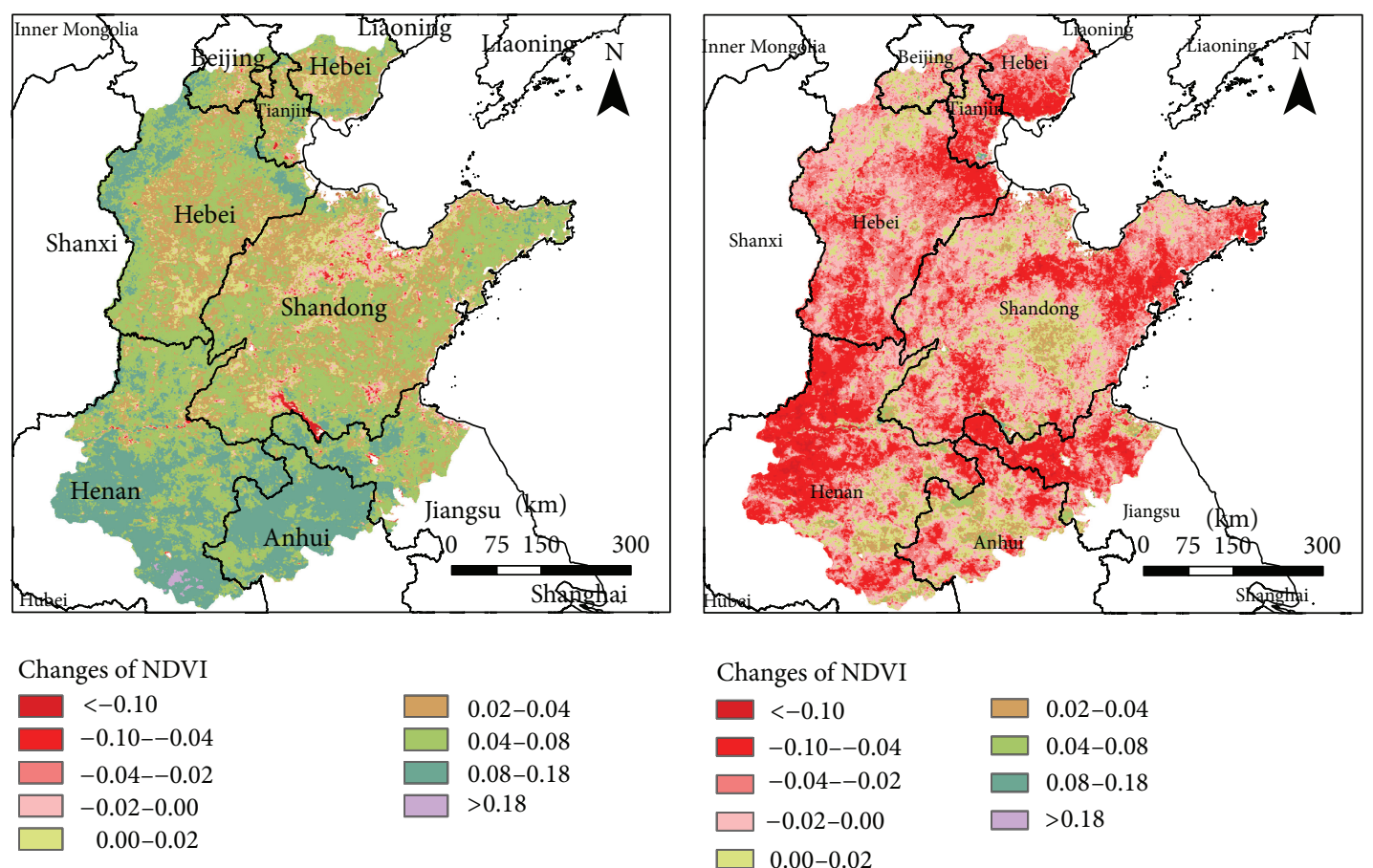

(a)

(b)
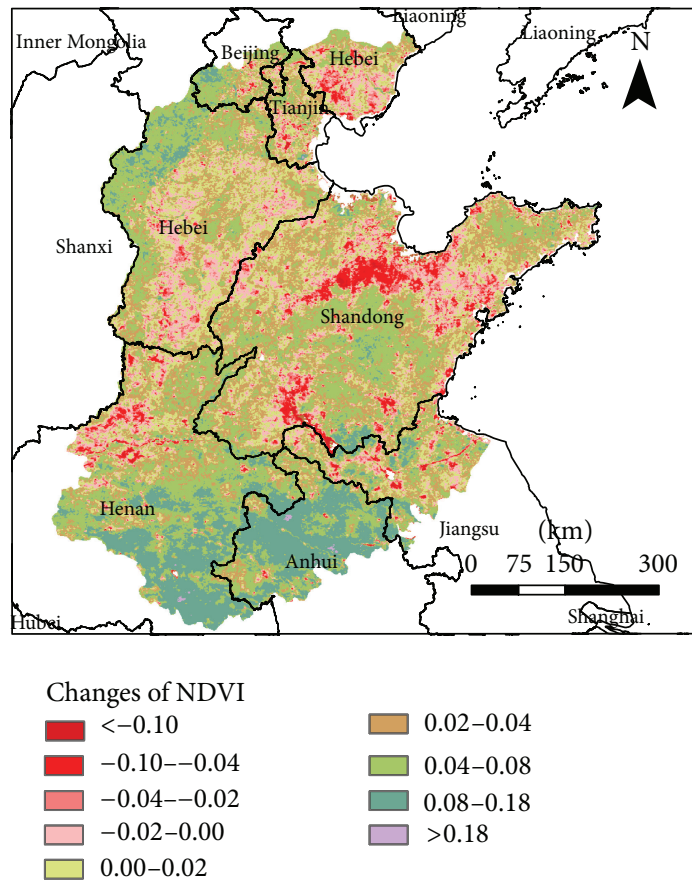

(c)

FIgure 6: Changes of NDVI of the North China Plain during (a) 2000-2004; (b) 2004-2008; and (c) 2000-2008.

cultivated land to other land use types, especially the conversion from cultivated land to built-up land. As cultivated land is the major land use types in the study area, thus we focus on the cultivated land conversion. In the North China Plain, cultivated land is mainly converted to built-up land (67\%), forest land (9.1\%), and grassland (12.4\%) (Figure 7).
2.4. Associations between Climate Factors and Land Degradation. We investigated the relationship between NDVI (from year 2000 to 2008) and climate factors. The relationship between NDVI and climate indicators is widely analyzed in many previous studies, which have confirmed that vegetation changes are closely related to changes in the climate factors 


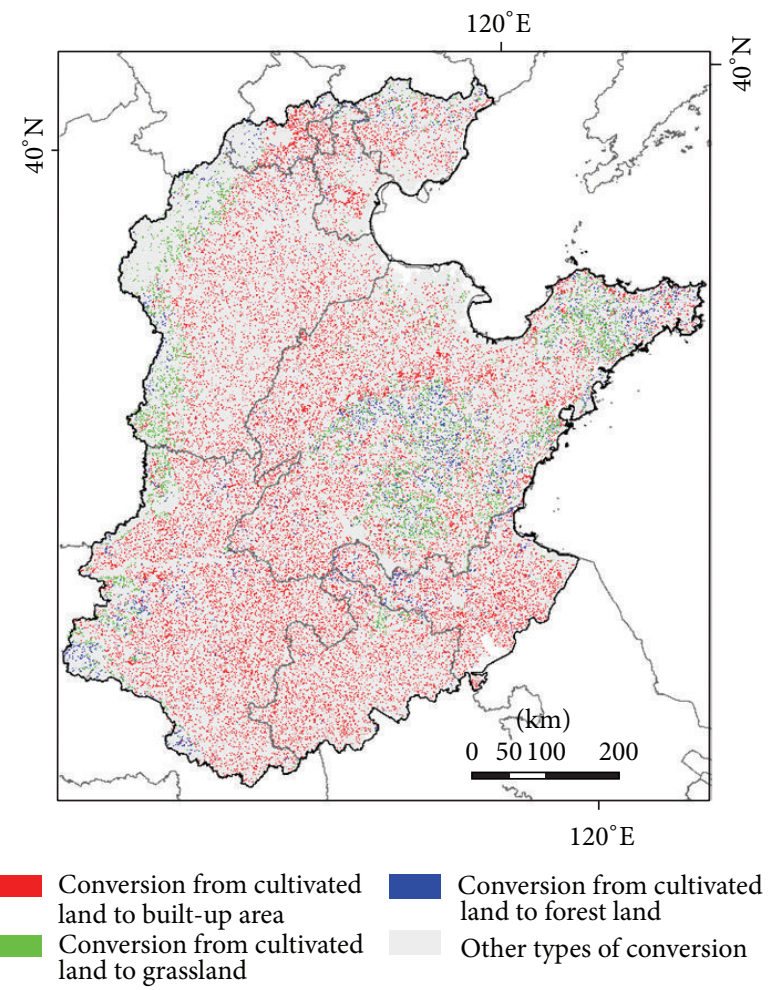

FIGURE 7: Land conversion from cultivated land to three major land use types during 2000-2008.

at the global or regional scale. In particular, it is widely acknowledged that the temperature and rainfall are the most significant factors influencing the ecosystem characteristics and distribution. We sampled the value of the NDVI, rainfall, and temperature and calculated their annual average values in the whole North China Plain. The mean NDVI, temperature, and rainfall for the study area were plotted along a nineyear time series (Figure 8 ). Figure 8 visually showed that the average NDVI experienced a fluctuated increasing trend, and the average rainfall and temperature slightly showed an increasing trend with some fluctuations.

Specifically, to study the responses of NDVI to the climate change, we analyzed the spatial correlation of NDVI with rainfall and temperature using the correlation analysis at the pixel scale. Figure 9 showed the spatial distribution of the correlation of NDVI with rainfall and temperature, respectively. It shows that the rainfall has a strong effect on NDVI, and there was a positive correlation between rainfall and NDVI in most parts of the study area, especially in the northern part of the study area where it showed a high correlation. As to the relationship between NDVI and temperature, there was generally a positive relationship between NDVI and temperature, which only in the northern part of the study area showed negative relationships.

\section{Assessments of the Driving Forces of Land Degradation}

The causes of land degradation are numerous, interrelated, and complex. The relationship between direct and underlying

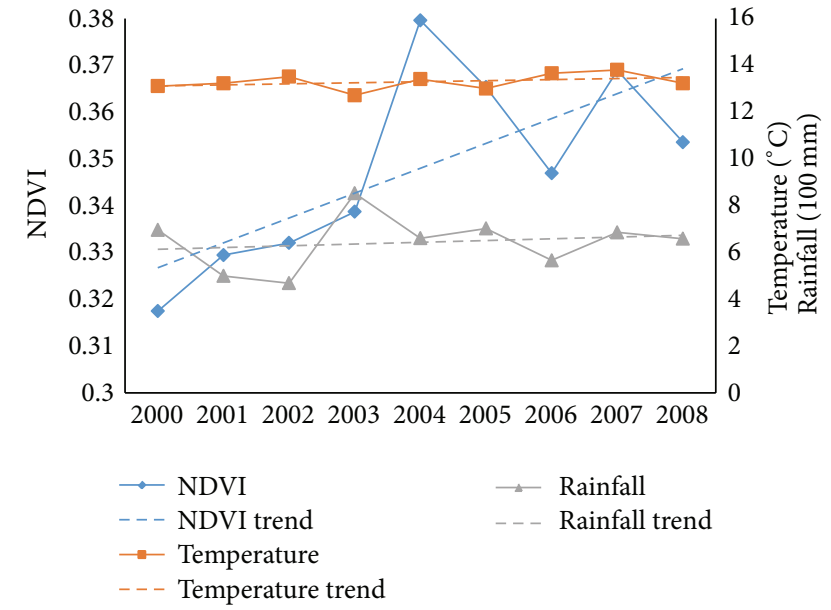

FIGURE 8: Changing trend of spatially aggregated annual NDVI, rainfall, and temperature.

causes of land degradation is complex also, and the impact of underlying factors is context specific [33]. Quite often, the same cause may lead to diverging consequences in different contexts because of its varying interactions with other proximate and underlying causes of land degradation. This implies that targeting only one underlying factor is not sufficient in itself to address land degradation. It is necessary to take into account a number of underlying and proximate factors when designing policies to prevent or mitigate land degradation. For our model specification, it is essential to 

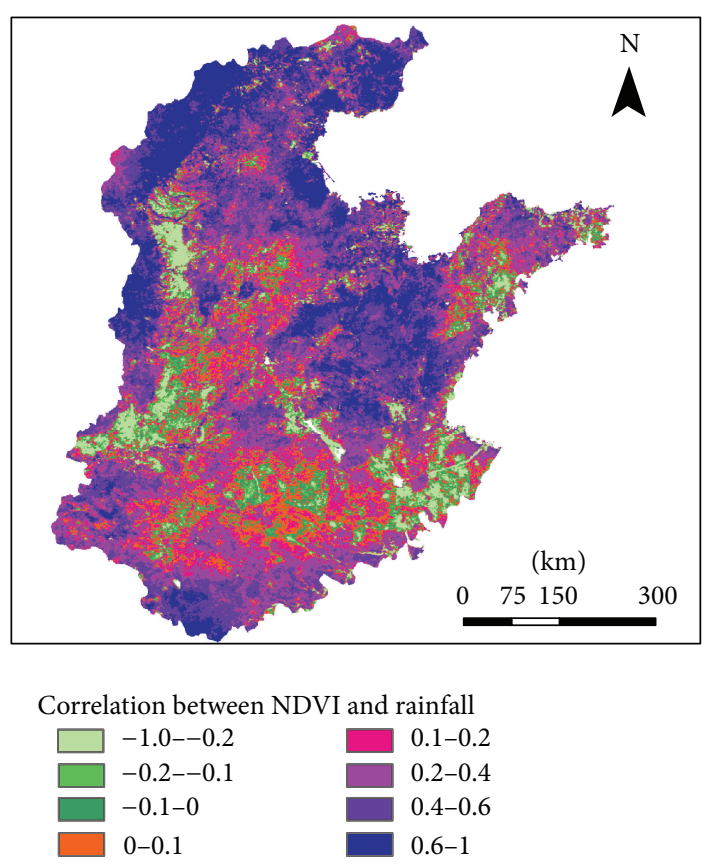

(a)
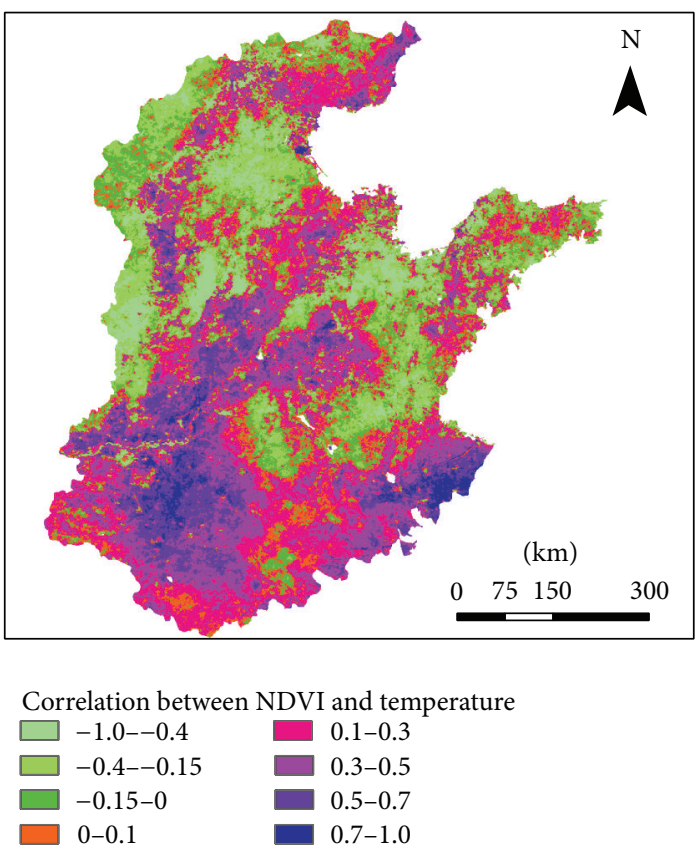

(b)

FIGURE 9: Spatial patterns of correlation (a) between annual average NDVI and rainfall and (b) between annual average NDVI and temperature at the pixel level in the North China Plain.

identify the effects of various combinations and interactions of underlying and proximate causes of land degradation in a robust manner rather than only analyze the individual cause of land degradation. In this regard, we try to identify the key underlying and proximate causes of land degradation. In this part, we conducted econometric analysis of the causes of land degradation in the North China Plain with the binary logistic regression model.

We constructed the model for estimating causes of land degradation or land improvement at the county level, using annualized data, and the model specification is as follows:

$$
\operatorname{Logit} Y_{t}=\beta_{0}+\beta_{1} \Delta x_{1 t}+\beta_{2} \Delta x_{2 t}+\beta_{3} x_{3}+\beta_{4} x_{4}+\varepsilon_{i t},
$$

where $Y_{t}=1$, if $\mathrm{NDVI}_{t}-\mathrm{NDVI}_{t-1} \geq 0$ and $Y_{t}=0$ if $\mathrm{NDVI}_{t}-\mathrm{NDVI}_{t-1}<0 ; x_{1 t}=$ a vector of biophysical causes of land degradation (e.g., climate conditions, topography, and soil fertility constraints); $x_{2 t}=$ a vector of demographic and socioeconomic causes of land degradation (e.g., population density, per capita GDP, rural farmers' per capita income, agricultural intensification); $x_{3}=$ a vector of variables representing access to infrastructure services (e.g., distance to expressway, distance to high way, and distance to other ways); and $x_{4}=$ a vector of variables representing land use changes (e.g., county-level percentage of land conversion from cultivated land to built-up land, forest land, and grassland during the years 2000-2008).

$Y_{t}$ is a binary variable that is being used to identify whether land degradation happens; if $Y_{t}$ equals or is larger than zero, then we assume that there happens land improvement; otherwise there happens land degradation. Furthermore, we applied a binary panel logit regression model to simultaneously study the relationship between land degradation conditions and all other variables. Table 1 illustrates the results of the regression. The results are to be interpreted with extreme caution due to the complex and multidirectional relationship between NDVI changes and the selected variables. Note that the results might not indicate a causal relationship but only an association between NDVI and the selected biophysical and socioeconomic variables [21].

The climate changes are significantly related with the land degradation conditions which are represented by the changes in NDVI. As expected, increments in temperature and rainfall are positively related with the increases in NDVI, and increases in temperature and rainfall will significantly contribute to land improvement. Land use change is also the major driving force of land degradation. The results showed that the conversion from cultivated land to grassland and forest land will contribute to land improvement, which corresponded to increase in NDVI, while the conversion from cultivated land to built-up land would lead to land degradation. Among the land conversions, only the conversion from cultivated land to grassland significantly affects the land degradation. In comparison, climate change plays a much more important role than land use change in land degradation. Besides, agricultural intensification represented by fertilizer utilization is significantly and positively related with land improvement, as fertilizer application increases soil carbon [34], which could correspond to an increase in NDVI. Increases in the population density would lead to land degradation but not significantly. According to the previous studies, the impact of population density on land degradation is ambiguous, while our results suggested that there would 
TABLE 1: Results for binary panel logistic regression analyses for the biophysical and socioeconomic driving forces of land degradation.

\begin{tabular}{|c|c|}
\hline $\begin{array}{l}\text { Land degradation conditions } Y \text { (1 represents land } \\
\text { improvement and } 0 \text { represents land degradation) }\end{array}$ & Coef. \\
\hline$\Delta$ Rainfall (mm) & $3.221^{* * *}$ \\
\hline$\Delta$ Temperature $\left({ }^{\circ} \mathrm{C}\right)$ & $1.025^{* * *}$ \\
\hline $\begin{array}{l}\text { Percentage of land conversion from cultivated land } \\
\text { to built-up land (\%) }\end{array}$ & -0.326 \\
\hline $\begin{array}{l}\text { Percentage of land conversion from cultivated land } \\
\text { to forest land }(\%)\end{array}$ & 1.788 \\
\hline $\begin{array}{l}\text { Percentage of land conversion from cultivated land } \\
\text { to grassland }(\%)\end{array}$ & $8.507^{*}$ \\
\hline$\Delta$ Fertilizer utilization per unit area $(\mathrm{kg} / \mathrm{ha})$ & $0.506^{* *}$ \\
\hline$\Delta$ Population density (ten thousand people $/ \mathrm{km}^{2}$ ) & -11.282 \\
\hline $\begin{array}{l}\Delta \text { Rural farmers' per capita income (ten thousand } \\
\text { yuan) }\end{array}$ & -0.076 \\
\hline $\begin{array}{l}\Delta \text { Per capita gross domestic production (ten } \\
\text { thousand yuan) }\end{array}$ & 0.0004 \\
\hline $\begin{array}{l}\Delta \text { Share of production value of agriculture animal } \\
\text { husbandry and fishery in GDP }(\%)\end{array}$ & $-1.672^{*}$ \\
\hline $\operatorname{DEM}(\mathrm{km})$ & 3.214 \\
\hline Slope (degree) & -0.018 \\
\hline Soil organic matter $(\%)$ & $0.446^{* * *}$ \\
\hline Distance to highway $(\mathrm{km})$ & $0.002^{*}$ \\
\hline _cons & 0.032 \\
\hline
\end{tabular}

Note: ${ }^{*}$ significant at the $10 \%$ level; ${ }^{* *}$ significant at the $5 \%$ level; and ${ }^{* * *}$ significant at the $1 \%$ level.

be more serious land degradation in areas with higher population density [35]. The population growth will lead to increasing demand for housing and other facilities, which in turn can lead to increase of impervious surface as a result of urban development and infrastructure construction and deforestation. Rapid economic development, which can be represented by changes in the per capita GDP, shows that an increase in both GDP and NDVI had positive impacts on land quality, suggesting the role the ecosystem service could play in economic growth and prosperity. Economic development would stimulate the land improvement, but such impacts were not significant, while the rural economic development, represented by rural farmers' per capita income, showed negative relationship with land improvement, suggesting that the NDVI will decrease as the rural farmer's income increase. It may be due to the fact that rural economic growth develops at the cost of intensive land use practice, which contributes to environmental degradation further leading to the land degradation. In addition, the increases in the share of the primary industry (agriculture, animal husbandry, and fishery) in GDP significantly corresponded to the decrease in NDVI. As production value of the agriculture increases mostly resulted from the investment into agricultural production, such as fertilizer, pesticide, and farm machinery, not from natural land quality improvement. In addition, the geographic and topographic factors also affect the land degradation. As to the topographical factors, the results showed that the higher the elevation and the slower the slope, the less serious the land degradation. The impact of elevation was not significant, while it may suggest that, in the areas with higher elevation, there would be less impacts of anthropogenic factors on the land degradation. The slope had clear significant impacts on land degradation, suggesting that steep slopes would lead to land degradation more easily, as steep slope regions were more vulnerable to severe water-induced soil erosion. As to the soil fertility represented by soil organic matter, the results showed that the higher the soil fertility was, the less the possibility of land degradation is. Besides, the distance to highway was significantly positively related with land improvement, which suggested that the larger distances to road network meant that there was less human disturbance, less infrastructure development, and land use changes, which would exert less impacts on the land degradation.

\section{Conclusions and Discussions}

Land degradation or improvement is an outcome of many highly interlinked direct and underlying causes, including natural, socioeconomic, and related agricultural practices. In China, many types of land degradation are occurring, such as grassland degradation, deforestation, and cultivated land degradation. In this paper, we conducted an empirical study in the North China Plain and analyzed the basic grain production changes, the changing trend of NDVI, the spatial pattern of relationship between climatic factors and NDVI. Further taking NDVI as a proxy for land degradation and improvement, we applied an econometric model to analyze the causes of land degradation.

According to the analyses, both the grain production and grain yield of the North China Plain showed an increasing trend during the years 2000-2008; however, estimation based on the remotely sensed NDVI data showed that the North China Plain still experienced land degradation. Degraded areas have been expending in the northern part of the study area, though many parts of the study area showed land improvement. Based on the correlation analysis, the increases in temperature and rainfall corresponded to the increase in NDVI in most parts of the North China Plain, though some parts of the study area showed negative correlation between NDVI and temperature and rainfall. Further, according to the binary panel logistic regression analysis, the results showed there were strong impacts of some key biophysical and socioeconomic variables on land degradation. Some of these relationships were consistent with conclusions in previous case studies, while others showed complex differences. The results for climate factors were not surprising, and increase in temperature and rainfall would contribute to land improvement. Different land use changes exert different impacts on land degradation. Unsurprisingly, increasing of forest land and grassland would benefit land quality, while urban expansion would lead to land degradation. Our estimation results about the positive effects of agricultural intensification represented by fertilizer utilization on land degradation were also as expected, and the soil organic matter was also a crucial positive factor for land quality conservation. Rural economic and agricultural development may lead to land 
degradation. The rural economic and agricultural production growth exerted negative impacts on land quality, which means the development of rural economy and agricultural production led to land degradation. The increases in rural farmers' per capita income and primary production value ratio did not result in the improvement of land quality, which may be due to the overexploitation of land with insufficient investment into the land conservation. In this regard, an effective response to land degradation needs increasing incentives of farmers to conserve their cultivated land and improve their access to the knowledge and inputs that are required for proper conservation. Promotion of such land improvements should be a development policy priority. During the process to promote rural economic development, the governments should also focus on the monitoring and assessment of land quality and make measures to improve land quality, and such improvement measures should be designed together with farmers to meet their prior needs and use appropriate techniques according to the local economic and social conditions. In addition, increasing accessibility to infrastructures may also have negative effects on land quality. Infrastructure development is the basis for regional prosperity, and a booming economy will result in more construction of infrastructure. The expansion of basic infrastructure of transportation such as roads, railways, and airports can further take up land resources and further result in land overexploitation and degradation. The covering of the soil surface with impervious materials as a result of urban development and infrastructure construction is known as soil sealing. Sealing of the soil and land consumption are closely interrelated; when natural, seminatural, and cultivated land is covered by impervious surfaces and structures, this will degrade soil functions or cause their loss. To reduce the impacts of infrastructure construction on land quality, the local government should take the assessment of land degradation into consideration during the construction of infrastructures.

Based on the above analysis results, to achieve sustainable land management, climate changes should be monitored so as to make adaptation measures to mitigate the impacts of climate changes on land quality; along with the socioeconomic development, investments and better land management for improving land quality should be definitely encouraged through appropriate policy measures; human activities that change the land surface, such as infrastructure constructions, should be regulated on the basis of the assessment of impacts on land quality, and corresponding land conservation measures should be taken during the construction process.

\section{Conflict of Interests}

The authors declare that there is no conflict of interests regarding the publication of this paper.

\section{Acknowledgments}

This research was financially supported by China National Natural Science Funds for Distinguished Young Scholar (Grant no. 71225005). The data support from the National
Natural Science Foundation of China (Grant no. 41171434) and the National Key Program for Developing Basic Science in China (Grant no. 2012CB955700) was also greatly appreciated.

\section{References}

[1] S. Bajocco, A. de Angelis, L. Perini, A. Ferrara, and L. Salvati, "The impact of land use/land cover changes on land degradation dynamics: a Mediterranean case study," Environmental Management, vol. 49, no. 5, pp. 980-989, 2012.

[2] E. B. Barbier, "The economic determinants of land degradation in developing countries," Philosophical Transactions of the Royal Society B: Biological Sciences, vol. 352, no. 1356, pp. 891-899, 1997.

[3] M. V. Sivakumar and N. Ndiang'ui, Climate and Land Degradation, Springer, 2007.

[4] E. Symeonakis, A. Calvo-Cases, and E. Arnau-Rosalen, "Land use change and land degradation in southeastern Mediterranean Spain," Environmental Management, vol. 40, no. 1, pp. 80-94, 2007.

[5] Millennium Ecosystem Assessment, Ecosystems and Human Well-Being: Desertification Synthesis, World Resources Institute, 2005.

[6] WMO, Cliamte and Land Degradation, World Meteorological Organization, 2005.

[7] Z. Bai and D. Dent, "Recent land degradation and improvement in China," Ambio, vol. 38, no. 3, pp. 150-156, 2009.

[8] X. Deng, J. Huang, S. Rozelle, and E. Uchida, "Growth, population and industrialization, and urban land expansion of China," Journal of Urban Economics, vol. 63, no. 1, pp. 96-115, 2008.

[9] F. Long, Introduction to the resources status in ChinaLand resources Jingchengnew.cn, 2013 (Chinese), http://www .jingchengw.cn/new/20130411/4927.htm.

[10] H. Li, Z. Liu, L. Zheng, and Y. Lei, "Resilience analysis for agricultural systems of North China plain based on a dynamic system model," Scientia Agricola, vol. 68, no. 1, pp. 8-17, 2011.

[11] X. Deng, J. Huang, S. Rozelle, and E. Uchida, "Cultivated land conversion and potential agricultural productivity in China," Land Use Policy, vol. 23, no. 4, pp. 372-384, 2006.

[12] H. Long, G. Tang, X. Li, and G. K. Heilig, "Socio-economic driving forces of land-use change in Kunshan, the Yangtze River Delta economic area of China," Journal of Environmental Management, vol. 83, no. 3, pp. 351-364, 2007.

[13] G. N. Bastin, G. Pickup, and G. Pearce, "Utility of AVHRR data for land degradation assessment: a case study," International Journal of Remote Sensing, vol. 16, no. 4, pp. 651-672, 1995.

[14] K. J. Wessels, S. D. Prince, P. E. Frost, and D. van Zyl, "Assessing the effects of human-induced land degradation in the former homelands of northern South Africa with a $1 \mathrm{~km}$ AVHRR NDVI time-series," Remote Sensing of Environment, vol. 91, no. 1, pp. 47-67, 2004.

[15] D. Singh, M. S. P. Meirelles, G. A. Costa, I. Herlin, J. P. Berroir, and E. F. Silva, "Environmental degradation analysis using NOAA/AVHRR data," Advances in Space Research, vol. 37, no. 4, pp. 720-727, 2006.

[16] Q. Jiang, X. Deng, J. Zhan, and S. He, "Estimation of land production and its response to cultivated land conversion in North China Plain," Chinese Geographical Science, vol. 21, no. 6, pp. 685-694, 2011.

[17] W. Shi, F. Tao, and J. Liu, "Changes in quantity and quality of cropland and the implications for grain production in the 
Huang-Huai-Hai Plain of China," Food Security, vol. 5, no. 1, pp. 69-82, 2013.

[18] C. J. Tucker, "Red and photographic infrared linear combinations for monitoring vegetation," Remote Sensing of Environment, vol. 8, no. 2, pp. 127-150, 1979.

[19] C. J. Tucker, H. E. Dregne, and W. W. Newcomb, "Expansion and contraction of the Sahara desert from 1980 to 1990," Science, vol. 253, no. 5017, pp. 299-301, 1991.

[20] M. Elhag and S. Walker, "Impact of climate variability on vegetative cover in the Butana area of Sudan," African Journal of Ecology, vol. 47, supplement 1, pp. 11-16, 2009.

[21] E. Nkonya, N. Gerber, P. Baumgartner et al., ZEF Discussion Papers on Development Policy, 2011.

[22] Z. G. Bai, D. L. Dent, L. Olsson, and M. E. Schaepman, "Proxy global assessment of land degradation," Soil Use and Management, vol. 24, no. 3, pp. 223-234, 2008.

[23] F. Yin, X. Deng, Q. Jin, Y. Yuan, and C. Zhao, "The impacts of climate change and human activities on grassland productivity in Qinghai Province, China," Frontiers of Earth Science, vol. 8, no. 1, pp. 93-103, 2014.

[24] G. Zhang, X. Xu, C. Zhou, H. Zhang, and H. Ouyang, "Responses of grassland vegetation to climatic variations on different temporal scales in Hulun Buir Grassland in the past 30 years," Journal of Geographical Sciences, vol. 21, no. 4, pp. 634-650, 2011.

[25] J. R. G. Townshend, C. Justice, D. Skole et al., "The $1 \mathrm{~km}$ resolution global data set: needs of the International Geosphere Biosphere Programme," International Journal of Remote Sensing, vol. 15, no. 17, pp. 3417-3441, 1994.

[26] J. Chen, P. Jönsson, M. Tamura, Z. Gu, B. Matsushita, and L. Eklundh, "A simple method for reconstructing a high-quality NDVI time-series data set based on the Savitzky-Golay filter," Remote Sensing of Environment, vol. 91, no. 3-4, pp. 332-344, 2004.

[27] J. Liu, M. Liu, D. Zhuang, Z. Zhang, and X. Deng, "Study on spatial pattern of land-use change in China during 1995-2000," Science in China Series D: Earth Sciences, vol. 46, no. 4, pp. 373384, 2003.

[28] J. Liu, Z. Zhang, X. Xu et al., "Spatial patterns and driving forces of land use change in China during the early 21st century," Journal of Geographical Sciences, vol. 20, no. 4, pp. 483-494, 2010.

[29] M. F. Hutchinson and P. E. Gessler, "Splines-more than just a smooth interpolator," Geoderma, vol. 62, no. 1-3, pp. 45-67, 1994.

[30] D. Xiangzheng, Simulation of Land System Dynamics, China Land Press, Beijing, China, 2008, (Chinese).

[31] P. A. Hancock and M. F. Hutchinson, "Spatial interpolation of large climate data sets using bivariate thin plate smoothing splines," Environmental Modelling \& Software, vol. 21, no. 12, pp. 1684-1694, 2006.

[32] X. Zhang, Q. Ge, and J. Zheng, "Impacts and lags of global warming on vegetation in Beijing for the last 50 years based on remotely sensed data and phonological information," Chinese Journal of Ecology, vol. 24, no. 2, pp. 123-130, 2005.

[33] E. Nkonya, N. Gerber, J. von Braun, and A. de Pinto, "Economics of land degradation," IFPRI Issue Brief 68, 2011.

[34] P. L. G. Vlek, G. Rodríguez-Kuhl, and R. Sommer, "Energy use and $\mathrm{CO}_{2}$ production in tropical agriculture and means and strategies for reduction or mitigation," Environment, Development and Sustainability, vol. 6, no. 1-2, pp. 213-233, 2004.
[35] S. J. Scherr, "A downward spiral? Research evidence on the relationship between poverty and natural resource degradation," Food Policy, vol. 25, no. 4, pp. 479-498, 2000. 

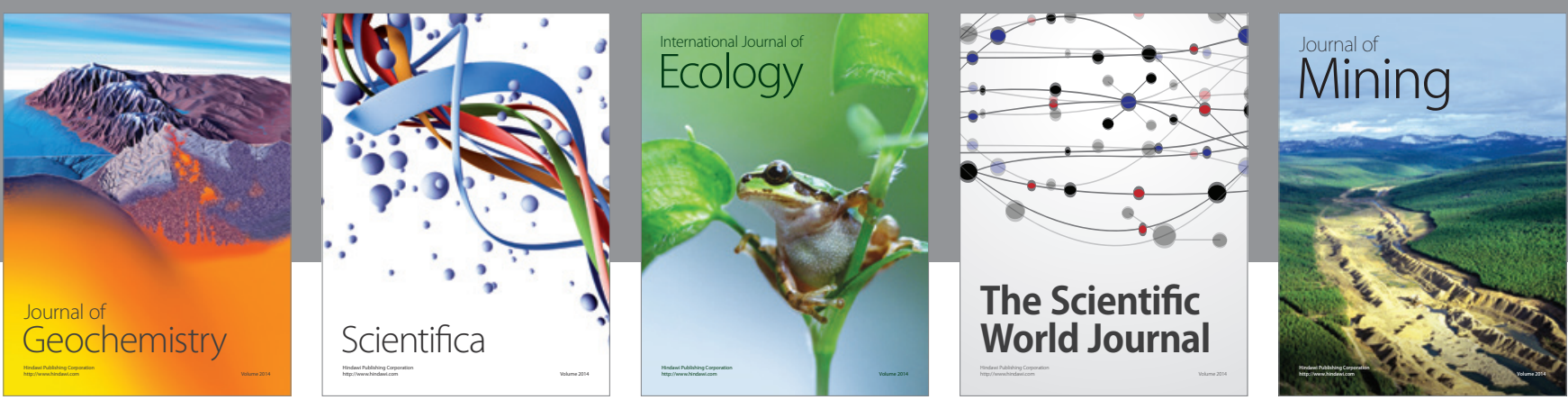

The Scientific World Journal
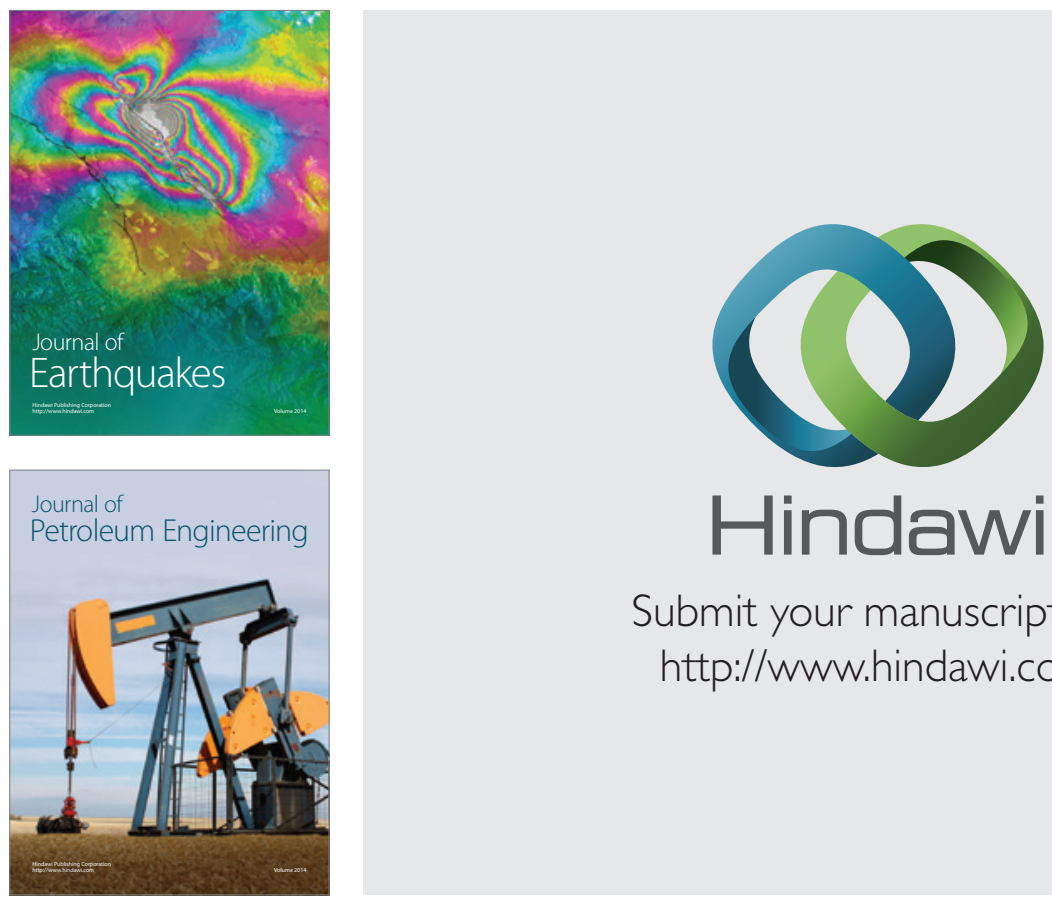

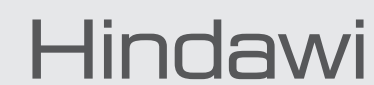

Submit your manuscripts at

http://www.hindawi.com
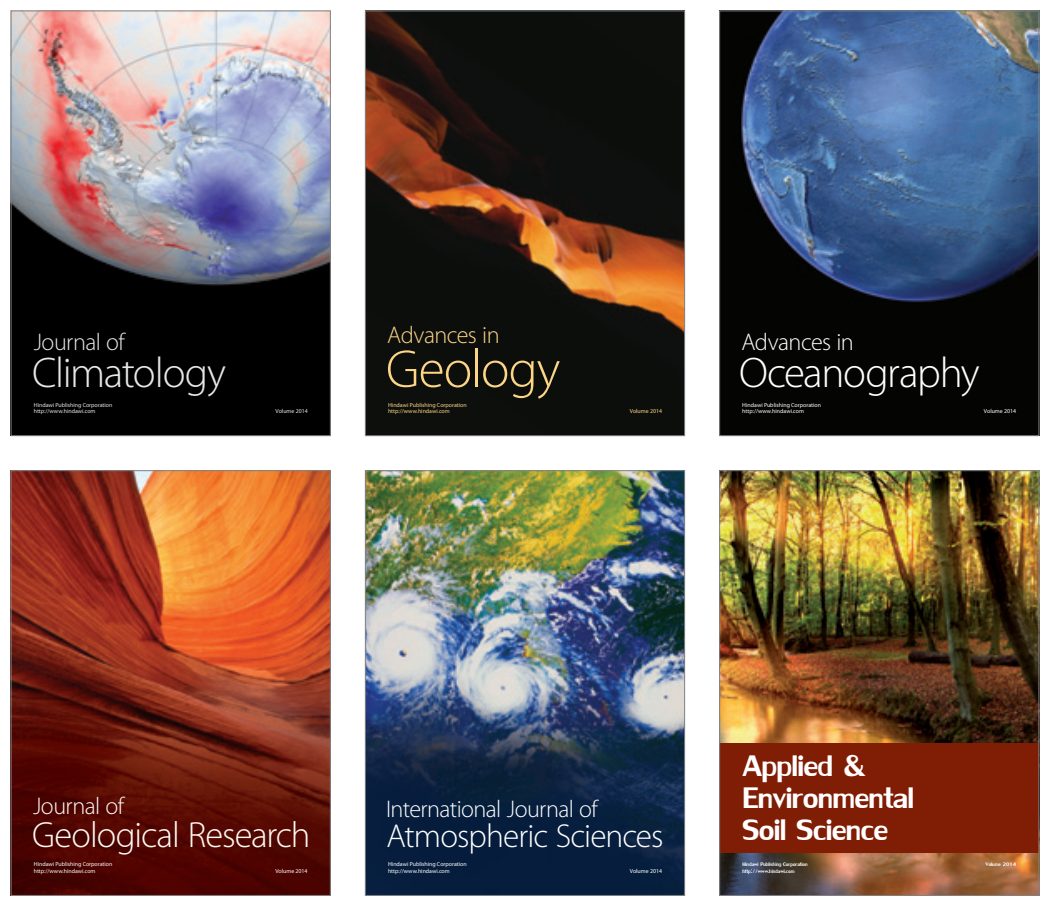
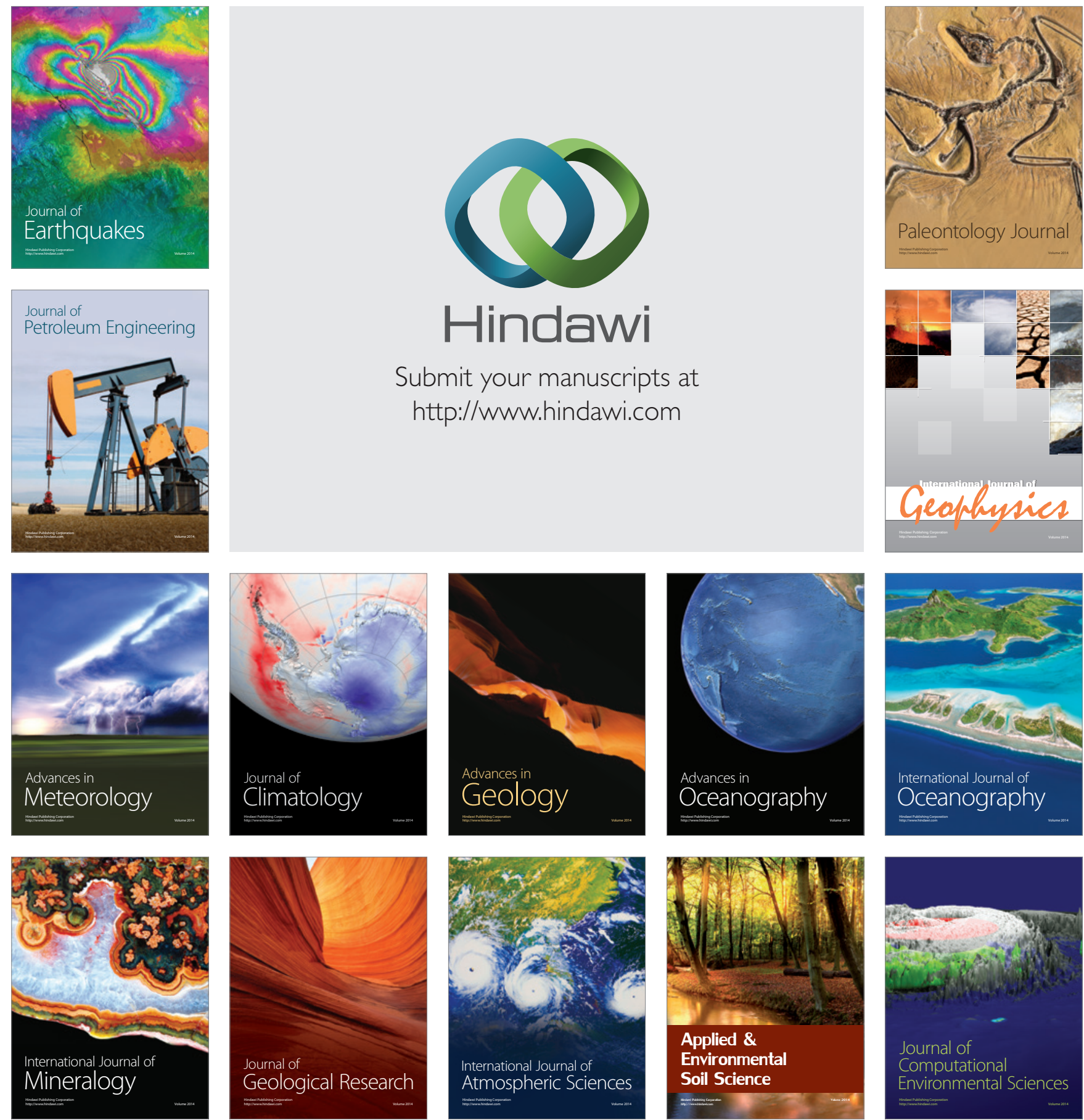